\title{
EL LIBRO DE EMBLEMAS DE ANDREA ALCIATO EN LA BIBLIOTECA NACIONAL DE ESPAÑA*
}

\author{
SAgrario López Poza \\ Universidade da Coruña \\ sagrario.lopez.poza@udc.es
}

\section{INTRODUCCIÓN}

ontar con una colección de libros de emblemas es un privilegio del que no todas las bibliotecas disfrutan. Las hay afortunadas, como las de algunas universidades cuyos fondos se vieron incrementados notablemente como consecuencia de la expulsión de los jesuitas de España por orden de Carlos III en 1767. Los comisionados del Gobierno acordaron que en las ciudades donde hubiera universidad, los fondos de bibliotecas de la Compañía de Jesús serían depositados en ellas, mientras que, en las ciudades sin universidad, las bibliotecas jesuíticas se enviarían a los seminarios. Es sabido que los jesuitas fueron muy perspicaces al percatarse de la importancia de la explotación de procedimientos retóricos que estimularan varios sentidos, especialmente la vista y el oído, y por ello tenían buenas colecciones de libros de emblemas y en su Ratio studiorum (1599), documento en que establecían el plan general de la «educación jesuita», incluyen ejercicios de creación mediante la palabra y la imagen con la composición de diversas modalidades emblemáticas en varias etapas y en diferentes tipos de clases y materias para exhibirlos colgados en cartelones en certámenes, festejos, ceremonias, entradas de personas notables, exequias, etc. También hay que decir que un número importante de jesuitas fueron autores de libros de emblemas.

Tras su expulsión, en España se vieron beneficiadas bibliotecas como la de la Universidad Complutense de Madrid y las universidades de Oviedo, Salamanca,

\footnotetext{
Este trabajo se ha realizado en el marco del proyecto I+D+I «Biblioteca Digital Siglo de Oro 6 (BIDISO 6)», con referencia: PID2019-105673GB-I00, financiado por el Ministerio de Ciencia e Innovación de España por el programa estatal de Generación del Conocimiento (2020-2022), y se integra en el Grupo de Investigación Hispania (G000208) de la Universidade da Coruña.
}

Edad de Oro, XL (2021), pp. 137-158, ISSN: 0212-0429 - ISSNe: 2605-3314

DOI: https://doi.org/10.15366/edadoro2021.40.006 
Santiago de Compostela, Sevilla, Granada, Valencia, Valladolid y Zaragoza. Por ello, una biblioteca que no haya sido beneficiada por esa forma de incremento de sus fondos tiene más mérito si dispone de una buena colección de libros de emblemas, y ese es el caso de la Biblioteca Nacional de España.

Entre las diversas modalidades de la Emblemática (los «emblemas», las «divisas» o «empresas», «invenciones» ocasionales exhibidas en torneos o justas, «jeroglíficos» para exponer en fiestas religiosas o exequias, affixiones o cartelones celebrativos en la recepción de personas importantes, «marcas de impresor» que se ajusten al modelo de las empresas, etc.), los «libros de emblemas» tienen una entidad propia y bien definida por sus características materiales, que les hace merecedores de la distinción como género editorial, marbete que se une al de género literario (López Poza, 2016).

Aunque conviene dejar claro que, como bien decía Daniel Russell (1985: 162) a propósito de los libros de emblemas franceses, no conviene establecer una categoría única en el concepto de «libro de emblemas» (pues existen variaciones importantes), por lo general consideramos un libro de emblemas aquel que acoge composiciones formadas por texto e imagen como un todo significativo, casi siempre distribuido en tres elementos — cuatro si al epigrama se añade un comentario en prosa- (imagen 1):

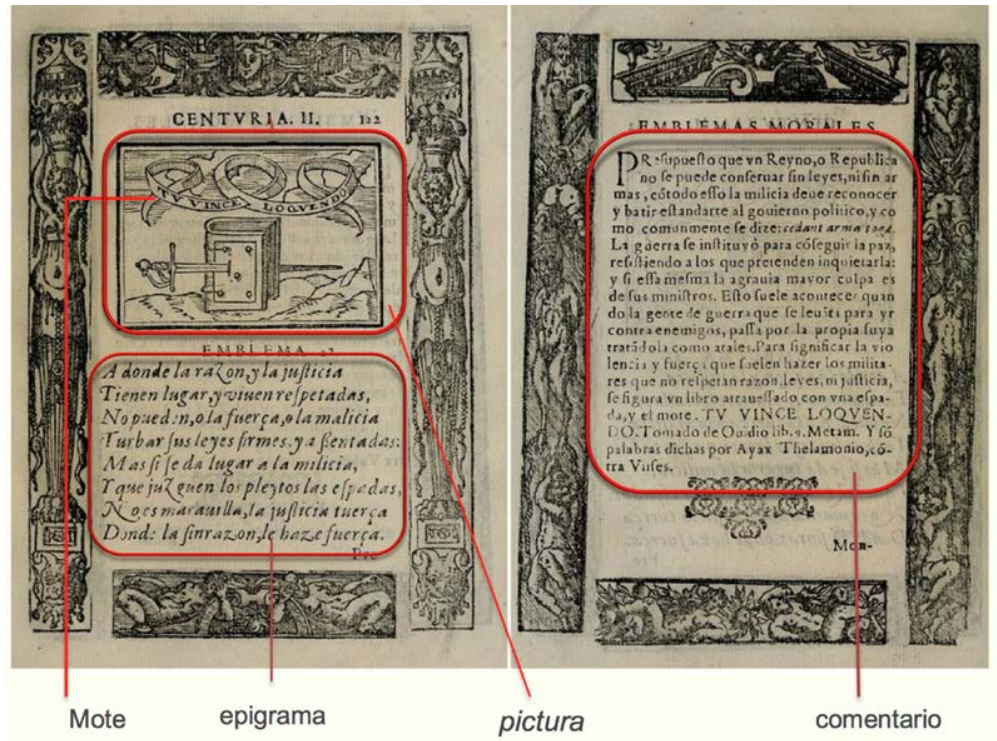

[IMAGEN 1]. Estructura frecuente de un libro de emblemas. (C) Sagrario López Poza. 
- $\quad$ un mote o lema (que en los siglos XVI y XVII lo llamaban el «alma del emblema») y que son unas palabras que sintetizan el concepto de lo que se pretende transmitir. A veces es un simple titulillo y, otras, una sentencia. Con frecuencia va expresado en latín, aunque el libro esté escrito en otra lengua;

- la pictura (como se suele llamar en los estudios de Emblemática) que es un grabado (xilográfico, calcográfico, etc.) con una imagen que ilustra el concepto «tratado» — «cuerpo», solían llamarlo en español en los siglos XVI y XVII- A veces la pictura va inserta en una cartela;

- un epigrama formulado en unos pocos versos que suelen aludir a la pictura y explican el sentido global de la composición.

A veces, como en este ejemplo que vemos de los Emblemas morales de Sebastián de Covarrubias (1610), al conjunto de los tres elementos se le añade un comentario en prosa. A ese tipo de textos a menudo se les llamaba Declaración del emblema.

Una variedad la constituían aquellos libros que prescinden del epigrama, de forma que cada «emblema» estaría compuesto por el mote, la pictura y un comentario en prosa. Las producciones de este tipo en español a menudo llevan en el título la palabra «empresas», con que pretenden distinguirse de los libros de emblemas de carácter más didáctico. Estos libros prescindían del epigrama por juzgarlo innecesario para unos lectores de más altura intelectual, desdeñando su presencia como propio de lectores jóvenes o que requerían de la gracia del verso y la facilidad que proporcionaban las rimas para aprender la lección moral transmitida. Las Empresas morales de Juan de Borja o las Empresas politicas ${ }^{1}$ de Saavedra Fajardo son buenos ejemplos.

Todos los elementos que forman parte de un emblema tienen una trayectoria histórica y cumplen funciones específicas. La imagen es de capital importancia para que el precepto moral que se pretende transmitir quede grabado en la memoria. A este respecto, Saavedra Fajardo, en el prólogo de sus Empresas políticas, señala al príncipe Baltasar Carlos (hijo de Felipe IV), a quien dirige su obra:

propongo a Vuestra Alteza la idea de un Príncipe político cristiano, representada con el buril y con la pluma, para que por los ojos y por los oídos - instrumentos del saber- quede más informado el ánimo de V.A. en la sciencia del reinar y sirvan las figuras de memoria artificiosa (1999: 169).

1 El título exacto era Idea de un príncipe político christiano representada en cien empresas (1640), pero con frecuencia se alude a la obra de forma abreviada. 
Los libros de emblemas fueron una consecuencia lógica de la evolución de la imprenta y el libro ilustrado con tacos xilográficos. A finales del siglo xv y comienzos del XVI, los impresores ensayaban fórmulas para publicar un género de moda, el de los proverbios ilustrados, que eran demandados por su interés didáctico-moralizante. Se ensayan diversas fórmulas para presentar el texto asociándolo con el grabado xilográfico que no solo daba como resultado un libro muy atractivo, sino que servía para fijar la atención y guardar en la memoria el precepto. Podemos ver (gracias a la digitalización que ofrece la Biblioteca Digital Hispánica de la Biblioteca Nacional de España) el incunable de 1493 realizado por el impresor alemán Pablo Hurus, asentado en Zaragoza: Exemplario contra los engaños y peligros del mundo (Inc/1994), una versión de una conocida colección de cuentos de origen oriental, Calila e Dimna.

El proverbio «Andando tras lo dudoso se pierde lo cierto» (imagen 2) se coloca en una filacteria al lado del grabado del perro que ilustra cómo la codicia le hace perder la carne que lleva en la boca, soltada para coger lo que en el agua del río parece ser un trozo mayor, no siendo más que el reflejo de la que llevaba.

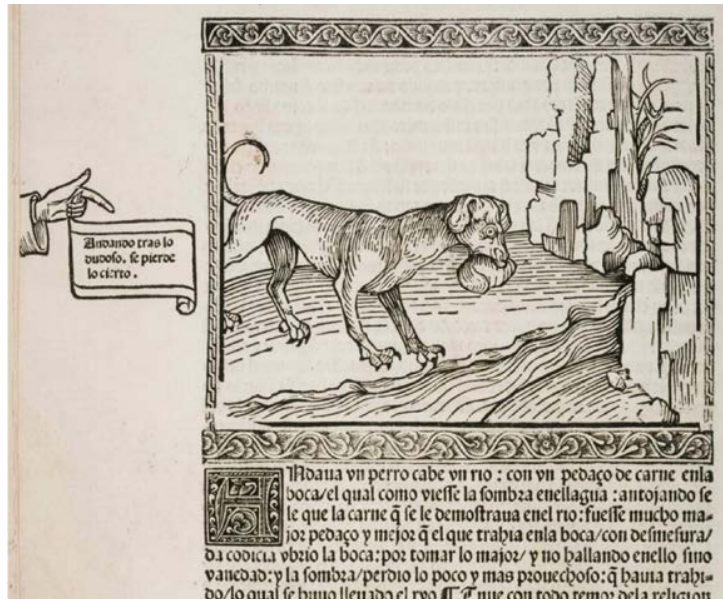

[IMAgEN 2]. Exemplario contra los engaños y peligros del mundo. Zaragoza: Pedro Hurus, 1493. $\mathrm{BNE}$, Inc/1994. Imagen procedente de los fondos de la Biblioteca Nacional de España.

No hay mucha diferencia con los libros de emblemas primitivos. Últimamente se están descubriendo obras que, como esta, pueden considerarse precursoras de un quehacer de los impresores que se había tenido poco en cuenta hasta ahora en el estudio de la emblemática. Así, Karl A. E. Enenkel (2018) pone de manifiesto que la estructura de lo que consideramos un emblema existía antes 
del que se ha venido considerando el libro inaugural del género, el Emblematum liber de Andrea Alciato (1531) que, según Enenkel, tuvo precursores como Johann von Schwarzenberg, que compuso dos libros ilustrados de emblemas entre 1510 y 1520 .

\section{El EMBLEMATUM LIBER DE AlCiATO y SU Difusión IMPRESA}

Aun siendo interesantes estos hallazgos recientes de libros ilustrados precursores de los libros de emblemas, el Emblematum liber de Andrea Alciato fue sin lugar a duda el iniciador del género. Alciato había estado colaborando con Johannes Soter en unas recopilaciones destinadas a estudiantes de epigramas de la Antología Planúdea, que incorporaban no una sino diversas versiones en latín de cada epigrama griego seleccionado. Participaron en esa tarea personas como Poliziano, Tomas Moro y Alciato, entre otros, y los editores (primero Johannes Soter, en 1528 y 1544, y luego Janus Cornarius, en 1529) se percataron del buen negocio que suponía dotar de esos materiales a maestros y, sobre todo, a profesores de universidad ${ }^{2}$.

Alciato copió ciento cuatro epigramas elaborados por él, precedidos cada uno por un titulillo, en un cuaderno que regaló por Navidad a su amigo Konrad Peutinger, consejero imperial. Algunos procedían de esas traducciones de la Antología Planúdea con que había contribuido en las antologías citadas y otros eran originales. Y aparecieron impresos en Augsburgo en un librillo en 8..$^{\circ}$ con el título: Emblematum liber, por el impresor y librero alemán Heinrich Steyner. La fecha del colofón es el 28 de febrero de 1531. El librito tiene cuarenta y cuatro hojas (es decir, ochenta y ocho páginas, que son cinco pliegos y medio) ${ }^{3}$ y de los ciento cuatro epigramas, noventa y ocho llevan un grabado xilográfico alusivo entre el título y el epigrama.

2 Alciato había incluido once traducciones de epigramas griegos en la selección de la antología que había publicado en Colonia Joannes Soter en 1525: Epigrammata aliquot Graeca Veterum Elegantissima, eademque Latine ab utriusque linguae viris doctissimis versa, atque nuper in rem studiosorum e diversis autoribus per Joannem Soterem collecta, nuncque primum edita. Coloniae: J. Soter, 1525. En 8. ․ Publicó también la traducción de otros 154 en la selección de Janus Cornarius publicada en Basilea en 1529: Selecta epigrammata graeca latine versa, ex septem Epigrammatum Graecorum libris. Accesserunt omnibus prioribus editionibus ac uersionibus plus quam quingenta Epigrammata, recens uersa, ab Andrea Alciato, Ottomaro Luscinio, ac Iano Cornario Zuiccauiensi. Basileae: ex aedibus Io. Bebelii, mense Avg 1529. En 8. ${ }^{\circ}$ (BNE, R-19721; 2/14944; 3/44394; y R/19741).

3 Descripción bibliográfica de la editio princeps por Alison Adams y Stephen Rawles en Alciato at Glasgow <https://www.emblems.arts.gla.ac.uk/alciato/bib-desc.php?id=A31a > [Consulta: 12/12/2019], así como en Green (1872: 2), Landwehr (1972: 23) y Scholz (1990: 213-254). 


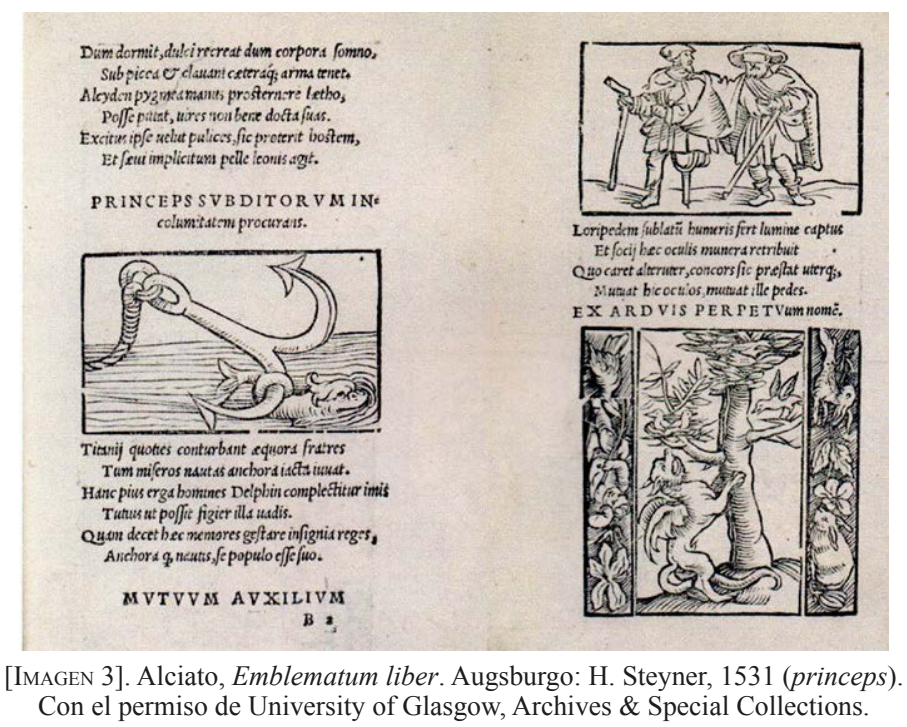

La editio princeps presenta abundantes irregularidades que enfadaron a su autor, quien no se sabe si dio el consentimiento para su publicación, pero que en cualquier caso no intervino en su composición, tal como comenta por carta al jurista Emilio Ferretti el 24 de marzo de 1532 (Drysdall, 2001), quejándose de erratas en los epigramas y desatinos en las picturae. Vemos, por ejemplo (imagen 3), cómo el impresor separa el mote de la pictura en el emblema Mutuum auxilium y comete el error de no reunir tampoco las tres partes en el siguiente emblema (al dejar el epigrama para la página siguiente), evidenciando que no es consciente de la estructura del nuevo género. Además, el dibujante que sirvió para elaborar el taco xilográfico, como no sabía latín, no vio que lo que dice el epigrama es que el cojo va encima de los hombros del ciego, y no uno al lado del otro. Aun con sus defectos, el libro de Alciato alcanzó tal éxito de venta que, a los dos meses de la primera edición, Steyner tuvo que imprimir la segunda.

¿De quién fue la idea genial de insertar un grabado entre el titulillo / mote y el epigrama? Es algo que lamentablemente desconocemos. Se cree que Konrad Peutinger, al recibir el cuaderno, habría encargado su publicación a Siegmund Grimm, un médico y farmacéutico casado con una pariente de Peutinger, que se había aventurado en la industria de la imprenta. Por dificultades económicas, Grimm sufrió bancarrota y en 1527 llegaron a manos del impresor Heinrich Steiner materiales de impresión procedentes de la imprenta de Grimm. No sabemos si los grabados ya estaban hechos, o una parte, o si se debió a Steyner el encargo de las xilografías de H. Schäufelein a partir de los diseños de Jörg Breu. 


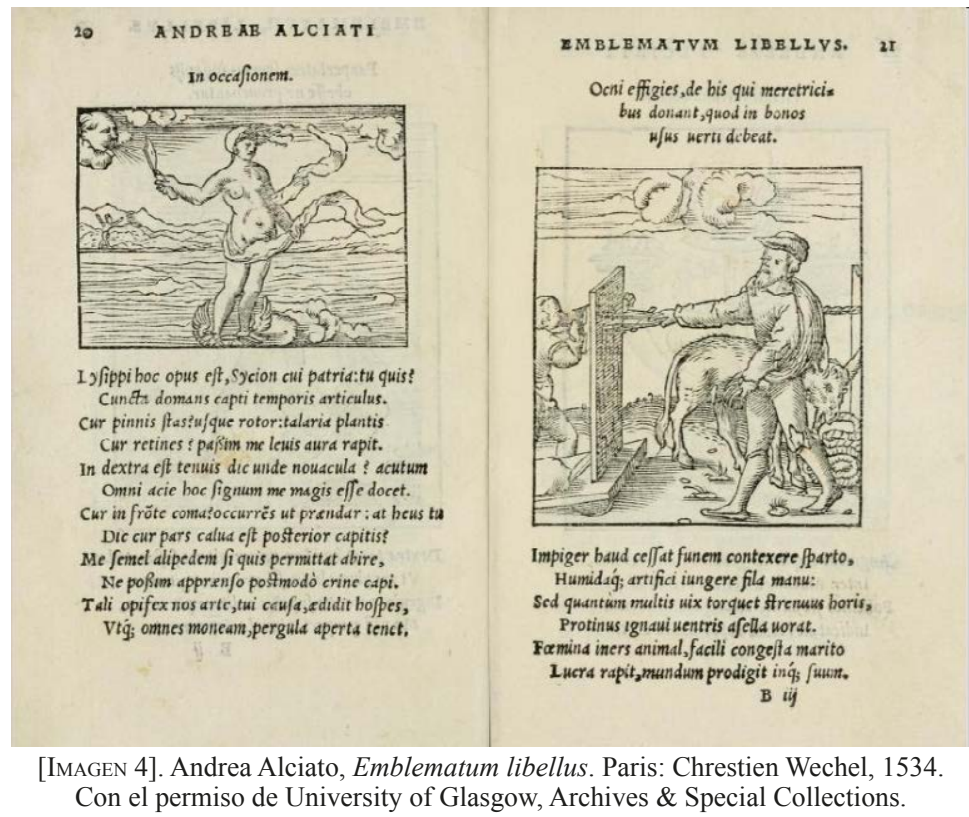

Tras las dos primeras ediciones, Steyner aún publicó otra en 1534. El modelo quedó perfeccionado ese mismo año, pero en una edición realizada en París, por Chrestien Wechel (impresor y librero flamenco) en que intervino el propio Alciato para corregir errores advertidos en las ediciones de Augsburgo (imagen 4). La estructura del emblema, formada por los tres elementos (mote, pictura y epigrama) se advierte al primer golpe de vista en esta edición, y fue imitado por muchos otros humanistas, desarrollándose así no solo un género literario, sino también un género editorial.

El libro de Alciato se convertiría en uno de los best sellers más difundidos a lo largo del tiempo. A finales del siglo XVII se habían producido ciento setenta y una ediciones de la obra no solo en latín, sino en francés, alemán, italiano, español e inglés. Desde su publicación han visto la luz hasta el día de hoy más de seis mil quinientos libros de emblemas. Y no solo fueron libros el vehículo de difusión de los emblemas, sino la emblemática aplicada, es decir, la utilización de emblemas en diferentes soportes de la cultura material: pinturas en techos o paredes de edificios, piezas de mayólica, tapices y elementos de artes decorativas, affixiones empleadas en la fiesta pública, etc., materiales cuya cuantía es difícil de estimar, dado su carácter más efímero, a causa de los avatares de guerras, inundaciones e incendios que han borrado una buena parte de esas reliquias del pasado. 
Hablamos, por tanto, de una producción ingente, estimada e influyente durante tres siglos, cuyo estudio implica a varias áreas de conocimiento que han hallado en los libros de emblemas información muy rica para aclarar aspectos de la cultura de los siglos XVI al XVIII: historia del arte, literatura - en distintas lenguas-, estudios sobre cultura clásica, literatura comparada, historia de las mentalidades, etc.

Los ciento cuatro emblemas iniciales de Alciato se fueron ampliando hasta alcanzar, en la edición de Petro Paulo Tozzi (Padua, 1621), el número final de 212 emblemas, todos ellos ilustrados y acompañados de comentarios de varios eruditos, por lo cual esta edición es la que suele seguirse para la numeración de los emblemas a partir del índice que realizaron Peter Daly y otros en 1985 (Index Emblematicus. Andreas Alciatus 1, 1985). Por poner un ejemplo, lo que en la edición primera no ocupaba ni una página, ocupa seis páginas en la de Padua de 1621. Ello se debe al acompañamiento de comentarios eruditos sobre cada emblema.

\section{Comentarios a los emblemas de Alciato}

A la muerte de Alciato, en 1550, comienza a ser considerado como un clásico, y su obra digna de ser comentada en latín (commentaria, annotationes, scholia) - algo infrecuente para autores modernos- - Poco antes, Barthélemy Aneau (c. 15101561), en la traducción que había realizado del libro de Alciato al francés, publicada en Lyon en $1549^{4}$, había tomado la iniciativa de añadir breves comentarios a muchos de los emblemas. En su edición, como en todas las demás patrocinadas por Guillaume Rouillé y realizadas por Macé Bonhomme (a excepción de la española) los emblemas están organizados en grupos temáticos, «lieux communs». Existe cierto debate sobre si Aneau, que trabajó en estrecha colaboración con sus colegas editoriales, fue responsable de esta reordenación de los emblemas de Alciato o si la idea partió de Rouillé.

A los comentarios de Aneau (en francés), siguieron otros eruditos en latín, que detallaban fuentes, explicaciones lingüísticas, de métrica, de retórica, etc., y aclaración de pasajes mediante glosas que explican hechos históricos, mitos, alegorías, etc. Eso hacía este tipo de comentarios un material de inestimable utilidad para los profesores de Latín, Retórica o Humanidades, tanto en escuelas de Gramática como en universidades.

\footnotetext{
$4 \quad$ Emblemes d'Alciat, de nouиeau translatez en François vers pur vers iouxte les Latins. Ordennez en lieux communs, avec briefues expositions \& figures nounelles appropriétees aux derniers Emblemes. Lyon: Macé Bonhomme, a costa de Guillaume Rouillé, 1549.
} 
Según el profesor de la Universidad de Münster, Karl A. E. Enenkel (2018: 233-263) $)^{5}$, entre 1556 y 1651 se produjeron aproximadamente sesenta y una ediciones del libro de Alciato en latín, y casi el $90 \%$ de ellas iban acompañadas de comentarios. Enenkel considera como iniciador del comentario erudito de emblemas al joven alemán de Baviera Sebastian Stockhamer, que realizó en latín un comentario sobre los emblemas de Alciato entre 1551 y 1552, mientras estaba en Coímbra. Publicó su trabajo en Lyon, en la imprenta de Jean de Tournes I y Guillaume Gazeau, en $1556^{6}$. Una nueva edición apareció en Lyon, por los mismos impresores (Iohannes Tronaesius y Gulielmus Gazeius) en $1561^{7}$ y más tarde otra edición en la oficina de Plantin de Amberes, en $1565^{8}$. Filipa Medeiros Araújo (Centro Interuniversitário de Estudos Camonianos de Coímbra) ha estudiado recientemente los comentarios de Stockhamer (Medeiros, 2020), y también Jesús Ureña (Universidad de Extremadura). Estas ediciones, que preceden en quince años a las más conocidas de Claude Mignault, presentan variaciones de contenido - es decir, que existen diversas versiones - y se advierten diferentes estados de impresión que están en proceso de estudio.

Otro humanista, el abogado francés Claude Mignault (1536-1606), produjo unos comentarios y los publicó en París (por Dionysius a Prato - es decir, Denys du Pré-) en $1571^{9}$. Esta edición solo contiene texto, sin las picturae a que hace referencia. Ofrece comentario de ciento noventa y siete emblemas numerados y también van añadidos (aunque sin numerar) los dedicados a quince árboles con que finaliza la colección completa de emblemas de Alciato. Estos comentarios eran reducidos, pero fueron aumentados notablemente en las siguientes ediciones de 1574 y 1577, con escolios amplios, que coinciden algunas veces con los del Brocense; no sabemos si porque se usaran las mismas fuentes o porque Mignault conociera ya los comentarios del maestro salmantino.

Capítulo IV, con título: «The Transformation of the Emblem Book into an Encyclopaedia: Stockhamer's Commentary on Alciato (1551/1556)».

6 Clarissimi viri D. Andreae Alciati, Emblematum Libri II. Nuper adiectis Sebastiani Stockhameri Germani in primum librum succinctis commentariolis. Lyon: Jean de Tournes et Guillaume Gazeau, 1556. Green (1872 n. ${ }^{\circ}$ 60); Adams, Rawles y Saunder (1999: F037).

7 Clarissimi viri D. And. Alciati Emblematum libri II / nuper ediectis Seb. Stockhameri Germ. in primum librum succinctis comentariolis. Lugduni: apud Ioan. Tronaesium et Guliel. Gazeium, 1561.

8 Emblematvm clarissimi viri D. Andrece Alciati Libri II. In eadem succincta commentariora, nunc multo, quàm antea, castigatiora \& longe locupletiora, Sebastiano Stockhamero Germano, auctore. Verfasser Alciati, Andrea, Verleger / Drucker Plantin, Christophe Erschienen. Antverpiae: Plantinus, 1565.

9 La primera edición de los comentarios de Claude Mignault fue Omnia Andreae Alciati Emblemata cum enarratione Claudii Minois, excerpta ex eiusdem in eadem emblemata commentariis. Paris: Dionysius a Prato [= Denys du Pré], 1571. 
Trece de las ediciones de los emblemas de Alciato conservadas en la Biblioteca Nacional de España llevan los comentarios de Claude Mignault, que obtuvieron muchísima difusión. Las más tempranas ediciones de estos comentarios con que cuenta la Biblioteca Nacional de España son dos de la oficina plantiniana de Amberes, de $1577^{10}$ y de 1581 . A ellos se suman la edición parisina de la imprenta de Jean Richer, de 1589 y otras.

Francisco Sánchez de las Brozas, el Brocense (1523-1600), catedrático de Retórica en la Universidad de Salamanca, realizó una edición en latín con comentarios de los emblemas de Alciato que se publicó en Lyon, en 1573, a costa del librero humanista Guillaume Rouillé ${ }^{11}$. Sin embargo, los comentarios fueron realizados a lo largo de los veinte años precedentes, posiblemente tomando como base la edición de Rouillé de 1550 (Merino Jerez-Ureña, 2003). Sánchez sentó las bases de una crítica científica; su trabajo es de erudición, apartado de tendencias didácticas o moralizadoras, dirigido a la comunidad científica europea del momento. Aporta las fuentes en que se inspiró Alciato y confronta las interpretaciones de autores italianos o franceses. Su comentario contiene doscientos once emblemas y la mayoría de las picturae son grabados xilográficos procedentes de los mismos tacos que se usaron en las ediciones patrocinadas por Rouillé entre 1548 y 1564, considerablemente gastados, pero posiblemente retocados. La Biblioteca Nacional de España dispone de ocho ejemplares de esa edición del Brocense y uno de ellos está digitalizado y disponible en la Biblioteca Digital Hispánica ${ }^{12}$.

Lorenzo Pignoria (1571-1631), sacerdote italiano nacido en Padua, que había realizado estudios de jurisprudencia sin concluirlos, muy aficionado a las antigüedades, realizó unas Notulae extemporariae in emblemata Andreae Alciati que, según Giuseppe Vedova (1836: 96), publicó por primera vez en 1613, en Augusta, en tamaño 4..$^{\circ}$, por Marco Valser, aunque no he encontrado ningún ejemplar reseñado. Posteriormente esos comentarios se incluyen en veinticuatro hojas que preceden sin numerar a la edición de los emblemas de Alciato de Pietro Paolo Tozzi (Padua, 1618, en $\left.8^{\circ}\right)^{13}$. Los comentarios de Pignoria — sin

10 Omnia Andreae Alciati v.c. emblemata: cum commentariis, quibus emblematum omnium aperta origine, mens auctoris explicatur, \& obscura omnia dubiáque illustrantur per Claudium Minoem diuionensem. Antuerpiae: Ex officina Christophori Plantini, architypographi Regij, MDLXXVII (1577).

11 Sánchez de las Brozas, Francisco, Francisci Sanctii Brocensis... Comment. in And. Alciati Emblemata: nunc denuò multis in locis accurate recognita et quamplurimis figuris illustrate. Lugduni: apud Guliel. Rouillium, 1573. Pedro Juan Galán Sánchez y Jesús Ureña preparan una edición y traducción completa de los comentarios a los emblemas del Brocense.

12 Signaturas: ER/1498, ER/1507, R/18845, R/20284, R/29727, R/37980, R/38117 y 8/3305.

13 Emblemata v. cl. Andreae Alciati: cu[m] imaginibus plerisque restitutis ad mentem auctoris. Patauij: apud Pet. Paulum Tozzium, 1618. 
imágenes - se colocan detrás de una breve biografía de Alciato y antes del comienzo de la obra, en que a los emblemas de Alciato en latín acompañan los comentarios de Mignault. La edición tiene muy notables xilografías. El mismo Tozzi volvió a publicar los comentarios de Pignoria en 1626, en $4 .^{\circ}$. Y fueron incluidos también en la edición de Tozzi de 1621 que hoy tomamos como referencia para numerar los emblemas de Alciato y que se cita a continuación. Pero incluso más tarde, se imprimieron los comentarios de Pignoria en dos ediciones, según información de Giuseppe Vedova (1836): una en Padua, en 1656, en 4. ${ }^{\circ}$, y la otra en Amsterdam, en 1674, en 12. .

En 1621, Johannes Thuilius (Johann Thuille, 1590-1630), médico y profesor de Retórica en la Universidad de Padua, que había enseñado previamente en Friburgo de Brisgovia (Alemania), preparó una edición de los emblemas de Alciato en Padua, costeada por Pietro Paolo Tozzi e impresa en la imprenta de Lorenzo Pasquato. En esta edición, Thuille amalgama sus propios comentarios con los de Claude Mignault (1574), Francisco Sánchez de las Brozas (1573) y Lorenzo Pignoria (1618). La Biblioteca Nacional de España dispone de dos ejemplares de esta edición de Thuilius para Tozzi de $1621^{14}$. Además de ser la edición más completa en cuanto a comentarios eruditos, ofrece por primera vez los doscientos doce emblemas que compuso Alciato con todas sus picturae en grabados xilográficos, pues en algunas ediciones, incluso en las más completas, solía faltar el emblema ochenta: Adversus naturam peccantes ${ }^{15}$ por considerar obscena su pictura. Esta es la edición definitiva o canónica.

Un español, Diego López (c. 1571-1656), nacido en Valencia de Alcántara (Cáceres), fue el último comentarista de Alciato. Estudió en la Universidad de Salamanca, donde fue alumno de Francisco Sánchez de las Brozas. Ejerció de preceptor de gramática latina y maestro de letras humanas en varias localidades: Olmedo, Toro, Santo Domingo de la Calzada (donde ocupó el cargo de catedrático de Latinidad y Letras Humanas), Cáceres y Mérida ${ }^{16}$. En sus últimos años, Diego López impartía clases en Toro a hijos de notables de la ciudad.

López publicó en Nájera, en 1615, un comentario de los emblemas de Alciato con el título: Declaración magistral de los Emblemas de Alciato con todas las Historias, Antigüedades, Moralidad y Doctrina tocante a las buenas costumbres,

\footnotetext{
14 Signaturas: 2/5496 y ER/1332.

15 Se incluyó por vez primera en la edición de Venecia, por los hijos de Aldo Manuzio en 1546, pero no se incorporó en muchas de las siguientes ediciones y volvió a aparecer en la de Padua de Paolo Tozzi de 1621. Ver Heckscher (1981: 291-311) y Manning (1997: 123-134).

16 Se conocen pocas referencias biográficas sobre Diego López. Remito a la tesis doctoral de Abigail Castellano López (2018), que recoge y actualiza las referencias de trabajos previos de Izquierdo Izquierdo (1989), Merino Jerez (1989) y Morcillo Expósito (2002).
} 
a su costa, en las prensas de Juan de Mongastón Foix (librero e impresor) ${ }^{17}$. Esta edición, producida por un tipógrafo no lo suficientemente experto, presenta abundantes irregularidades en paginación y en imposición de los grabados, variantes entre ejemplares que constituyen varios estados. Las picturae derivan en su mayoría de las treinta y seis ediciones de Lyon (que realizaron a veces con doble emisión Rouillé y Bonhomme) atribuidos a Pierre Eskrich (Pierre Vae), aunque invirtiendo en espejo la pictura en la mayoría de ellos como consecuencia de copiar la imagen y calcarla en el material de reproducción. En este aspecto, esta edición presenta la originalidad de emplear técnicas diferentes para producir los grabados (calcografía y xilografía). Algunas picturae han sido incisas con buril en cobre y otras (catorce) talladas en tacos de madera. Esto complicaría sobremanera la producción de los cuadernillos, pues unos tendrían que pasar, además de por la prensa ordinaria, por el tórculo. Esta circunstancia justifica las irregularidades que se evidencian en los diversos estados de la edición (que según el estudio de García Arranz - en prensa- son tres).

Los grabados evidencian la poca formación técnica de quien se ocupó de esta tarea, lo que daría grandes quebraderos de cabeza al autor (que se queja en el prólogo del altísimo coste económico que le supuso la publicación). La edición pone de manifiesto que imprimir un libro de emblemas era una empresa no apta para aficionados, pues requería competencia máxima en los procesos de composición, casado, imposición, impresión y alzado. Si esas condiciones no se daban, el producto presentaría numerosas irregularidades, como en este caso.

La Declaración magistral de López reproduce el mote, grabado y epigrama latino de las ediciones lionesas financiadas por Rouillé, añadiendo un extenso comentario que presenta un análisis filológico, histórico y mitológico de cada emblema, detallado, pero expresado con sencillez, a lo que añade la moralidad que debe extraerse del conjunto. Muy posiblemente el libro tuviera como principal objetivo servir de material de trabajo para los estudiantes de retórica latina y cultura clásica. López conocía bien los comentarios del Brocense, a quien respeta. En sus comentarios, algo desiguales, según los emblemas, alardea de sus amplios conocimientos de los clásicos. Al margen de su erudición filológica e histórica, carga el acento en la intención didáctico-moralizadora, religiosa, y trae glosas que poco tienen que ver con el pensamiento de Alciato. A pesar de todo, las ediciones de estos comentarios fueron muy leídas en España y América, por estar en español. La edición y comentario de López se ocupa de doscientos diez emblemas y no incluye el ya mencionado Adversus naturam peccantes ni Desidia (n. ${ }^{\circ} 80$ y 81 en la numeración que hoy seguimos, basada en la edición de Tozzi de 1621).

17 Los profesores José Julio García Arranz y Luis Merino Jerez preparan una edición del comentario de Diego López a los emblemas de Alciato. 
La Biblioteca Nacional de España conserva ocho ejemplares ${ }^{18}$ de esta edición, algunos de los cuales han sido analizados y contrastados por García Arranz (en prensa).

La Declaración magistral de los Emblemas de Alciato de Diego López se volvió a publicar en Valencia por tres veces: en 1655 (de ella la Biblioteca Nacional de España tiene tres ejemplares ${ }^{19}$, y uno de ellos disponible en la Biblioteca Digital Hispánica). De nuevo se imprimió en 1670 (por Jerónimo Villagrasa), de la que la Biblioteca Nacional de España tiene dos ejemplare ${ }^{20}$ (uno de ellos digitalizado en Biblioteca Digital Hispánica) y en 1684 por Francisco Mestre, de la que también tiene la Biblioteca Nacional de España tres ejemplares ${ }^{21}$.

\section{Traducción al español de los emblemas de Alciato}

El primero que tradujo al español los emblemas de Alciato y los dio a la imprenta fue Bernardino Daza Pinciano ${ }^{22}$ (1528-post 1576), jurista de Valladolid, que pasó unos años (de 1549 a 1551) en Francia para ampliar sus estudios de Derecho en Toulouse y publicó su traducción en Lyon, en 1549, en doble emisión: por el librero Guillaume Rouillé y su impresor, Macé Bonhomme, con el título: Los emblemas de Alciato en rhimas españolas. Declara que encontró una copia de los Emblemas corregida de la mano del propio Alciato. Emprende la traducción, según él, para no olvidar su lengua nativa. En el interesante prólogo, manifiesta que ha realizado una traducción bastante libre, utilizando una variedad de estrofas que se ajustan, a su manera, a la extensión de los epigramas latinos originales; ha optado claramente por las «coplas italianas» o «rimas» (octavas, sonetos y tercetos), manifestándose defensor del nuevo sistema poético frente a la forma en que comúnmente se plasmaba el epigrama común: coplas castellanas o redondillas. La versión poética es de escasa calidad, pero tiene indudable interés y se divulgó rápidamente por España. La Biblioteca Nacional de España conserva siete ejemplares de la emisión de Rouillé ${ }^{3}$ (uno de ellos digitalizado en Biblioteca Digital Hispánica) y cuenta también con dos ejemplares de la emisión de Macé Bonhomme ${ }^{24}$.

\footnotetext{
18 Signaturas: 4/53788, R/2597, R/14859, R/23100, R/23123, R/23124, R/26751 y R/31175.

19 Signaturas: 3/39318, M/9525 y U/9525. Digitalizado en Biblioteca Digital Hispánica el ejemplar U/9525.

20 Signaturas: 7/15150 y 3/33001. Este último reproducido en Biblioteca Digital Hispánica.

21 Signaturas: $2 / 26696,7 / 12604$ y R/2726.

22 Hubo diversas traducciones que quedaron manuscritas de las que no nos ocupamos aquí, por no atañer a los fondos impresos de la Biblioteca Nacional de España.

23 Signaturas: R/12332, R/1403, R/16584, R/3682, R/4145, R/6222 y R/8588.

24 Signaturas: U/10139 y R/4157.
} 
Recapitulando, la Biblioteca Nacional de España conserva por lo menos treinta ediciones de los emblemas de Alciato hasta finales del siglo XVIII (en realidad, veintinueve ediciones, pues una de ellas - Lyon, 1549- es la misma edición, pero con dos emisiones, como se ha dicho: una con portada de Guillaume Rouillé y otra con portada de Mathias Bonhomme). Se produjeron en los años 1544, 1548, 1549, 1550, 1560, 1564, 1566, 1573, 1577, 1581, 1589, $1600,1602,1608,1614,1615,1618,1621,1622,1655,1670,1676,1684$, $1692,1715,1724,1733,1749$ y 1781 . La mayoría están en latín, salvo siete ediciones en español (una con dos emisiones) y dos en francés ${ }^{25}$. Hay más de un ejemplar en algunas ediciones, lo que suma sesenta y cinco ejemplares. De ellos, hay reproducción digital en Biblioteca Digital Hispánica, en este momento (2020), de ocho ejemplares.

En cuanto a las ediciones que incluyen comentarios, se conserva en la Biblioteca Nacional de España una edición (Lyon, 1573) de los comentarios de Francisco Sánchez, el Brocense; diecisiete ediciones contienen los comentarios de Claude Mignault, y varios comentarios (de Mignault, Lorenzo Pignoria, Thuille y Francisco Sánchez, el Brocense) se incluyen en la edición de Padua, costeada por Tozzi e impresa por Lorenzo Pasquato, 1621, de la que la Biblioteca Nacional de España conserva dos ejemplares. De los comentarios de Diego López, la Biblioteca Nacional de España dispone de cuatro ediciones y dieciséis ejemplares (1615: ocho ejemplares; 1655: tres ejemplares; 1670: dos ejemplares y 1684: tres ejemplares).

Y respecto a traducciones, de la de Daza al español: Los emblemas de Alciato traducidos en rhimas españolas; añadidos de figuras y de nueuos emblemas en la tercera parte de la obra... En Lyon, por Guilielmo Rouillio, 1549, la Biblioteca Nacional de España cuenta con nueve ejemplares (siete de la emisión del librero-editor Guillaume Rouillé y dos de la emisión del impresor Macé Bonhomme).

\section{Manuscritos de los emblemas de Alciato en la Biblioteca Nacional de España}

Además de los libros impresos, la Biblioteca Nacional de España conserva curiosos manuscritos inéditos del libro de emblemas de Alciato que están esperando estudio detallado. Uno de ellos es el MSS $/ 1596^{26}$, cuya ficha solo

25 Para la identificación de ediciones y detalles bibliográficos, ver en bibliografía los registros: Campa (1989; 1990; 2001); Heckscher (1989); Tung (1989); y Adams, Rawles y Saunders (1999).

26 Andrea Alciati (1492-1550), Emblemas [Manuscrito] [Andrea Alciati, traducción castellana con glosas] S. XVII-XVIII, XI, 606 p.; 22 x 16 cm., Compra Librero Montes 1878. MSS/1596. bdh0000120734. 
indica «S. XVII-XVIII». Parecen unos comentarios originales basados en los del Brocense de 1573, pero en español (tanto los epigramas como el comentario) y posiblemente estaba concebido con ánimo de publicarlo. Para los epigramas, hasta el emblema cien, se ha servido de la traducción de Daza Pinciano en su edición de Lyon de 1549: Los emblemas de Alciato traduzidos en rhimas españolas, pero a partir del emblema ciento uno, los epigramas ya no aparecen, habiendo sido sustituidos por una glosa en prosa, seguida del comentario. El autor no parece haber seguido a Claude Mignault. El manuscrito lo está estudiando y editando Jesús Ureña. Al final del volumen, en una página (381) se incluyen «Los dísticos de Catón traduzidos en Romance por el licenciado Pedro García Barragán. Presbítero», en cinco redondillas. Pero nada puede asegurarnos que el autor haya sido este. El número de emblemas que incluye es de ciento noventa y siete, terminando con «La casada con el buboso». No incluye los quince emblemas sobre árboles con que finaliza la colección completa de emblemas de Alciato.

Otro manuscrito (MSS/8480) ${ }^{27}$ contiene doscientos once emblemas (es decir, que excluye, como la mayoría de las ediciones, el ochenta). La ficha data el manuscrito en el siglo XVIII e indica: «Emblemas de Alciato, en latín con su construcción y traducción castellana». En h. 1 se indica: «Es obra del Hermano Pedro Díaz Bote de los P.P. Ministros de los enfermos». Van en blanco los ff. 2 y $17 \mathrm{v}-18 \mathrm{r}$. El autor de este manuscrito copia los epigramas de Alciato y, a continuación, bajo el epígrafe «Contrucción», se van entreverando los textos latinos con su traducción literal al español siguiendo el texto de Diego López. Parece que estaba destinado a alumnos que aprendían gramática latina. Al igual que el anterior, está siendo objeto de estudio del profesor Jesús Ureña.

Concluimos ofreciendo, para mayor facilidad de consulta, una tabla con las ediciones impresas de los emblemas de Alciato y ejemplares (con signaturas), hasta finales del siglo XVIII, conservadas en la Biblioteca Nacional de España (excluyendo las copias en microfilm o microfichas). Se indica idioma y, en caso de que la edición se acompañe de comentarios, a quién se deben.

27 En el catálogo de manuscritos de la Biblioteca Nacional de España aparece: «Pedro Díaz Bote, [Emblemas de Alciato en latín con su construcción y taducción castellana por el hermano Pedro Díaz Bote, religioso de los PP. Ministros de los enfermos]. Siglo xviII, papel, 155 x 99 mm. 183 ff.». Tiene por signatura MSS/8480, y está disponible en Biblioteca Digital Hispánica bdh0000145885. 


\begin{tabular}{|c|c|c|c|}
\hline Edición & $\begin{array}{c}\text { Signaturas de } \\
\text { ejemplares }\end{array}$ & Idioma & Comentarios \\
\hline $\begin{array}{l}\text { Alciati, Andrea, Andreae alciati Emblema- } \\
\text { tum libellus. Lugduni: Iacobus Modernus } \\
\text { excudebat, 1544. Encuadernado con otras } \\
\text { obras. }\end{array}$ & $3 / 34465(3)$ & Latín & \\
\hline $\begin{array}{l}\text { Alciati, Andrea, Emblemata Andreae Alcia- } \\
\text { ti iurisconsulti clarissimi. Lugduni: apud } \\
\text { Gulielmum Rouillium..., } 1548 \text { (excudebat } \\
\text { Mathias Bonhomme). }\end{array}$ & $\mathrm{R} / 39862$ & Latín & \\
\hline $\begin{array}{l}\text { Alciati, Andrea, Los emblemas de Alciato } \\
\text { traducidos en rhimas españolas; añadidos } \\
\text { de figuras y de nueuos emblemas en la ter- } \\
\text { cera parte de la obra... Lyon: Guilielmo } \\
\text { Rouillio, } 1549 \text {. } \\
\text { Un ejemplar digitalizado en Biblioteca } \\
\text { Digital Hispánica. Esta edición tuvo doble } \\
\text { emisión, posiblemente por acuerdo entre el } \\
\text { librero-editor Rouillé y el impresor Bon- } \\
\text { homme. Estos ejemplares son de la emisión } \\
\text { con portada de Guillaume Rouillé. }\end{array}$ & $\begin{array}{l}\mathrm{R} / 12332 \\
\mathrm{R} / 1403 \\
\mathrm{R} / 16584 \\
\mathrm{R} / 3682 \\
\mathrm{R} / 4145 \\
\mathrm{R} / 6222 \\
\mathrm{R} / 8588\end{array}$ & Español & \\
\hline $\begin{array}{l}\text { Alciati, Andrea, Los emblemas de Alciato } \\
\text { traduzidos en rhimas españolas [por Bernar- } \\
\text { dino Daza Pinciano]; añadidos de figuras y } \\
\text { de nueuos emblemas en la tercera parte de la } \\
\text { obra. Lyon: Mathias Bonhomme, } 1549 \text {. } \\
\text { Esta edición tuvo doble emisión, posible- } \\
\text { mente por acuerdo entre el librero-editor } \\
\text { Rouillé y el impresor Bonhomme. Estos } \\
\text { ejemplares son de la emisión con portada } \\
\text { de Macé Bonhomme. }\end{array}$ & $\begin{array}{l}\mathrm{U} / 10139 \\
\mathrm{R} / 4157 \\
\end{array}$ & Español & \\
\hline $\begin{array}{l}\text { Alciati, Andrea, Emblemata D.A. Alciati, } \\
\text { denuo ab ipso autore recognita, ac, quae } \\
\text { desiderabantur, imaginibus locupletata: } \\
\text { accesserunt noua aliquot ab autore em- } \\
\text { blemata suis quoque eiconibus insignita. } \\
\text { Lugduni: apud Mathiam Bonhomme, } \\
1550 .\end{array}$ & $3 / 13019$ & Español & \\
\hline $\begin{array}{l}\text { Alciati, Andrea, Andr. Alciati iuriscons. me- } \\
\text { diolanensis, Tractatus, Orationes, Adnota- } \\
\text { tiones in C. Tacitum, \& Emblemata... Tomi } \\
\text { sexti pars vnica, Petrus Fradin excudebat, } \\
1560 .\end{array}$ & $\mathrm{R} / 32060$ & Latín & \\
\hline $\begin{array}{l}\text { Alciati, Andrea, Emblemes d'Alciat, de } \\
\text { nouveau translatez en francois vers pour } \\
\text { vers pour versiouxte les latins, ordonnez en } \\
\text { lieux communs, avec briefues expositions et } \\
\text { figures nouvelles appropriees aux derniers } \\
\text { emblemes. Lyon: Guill. Rouille, } 1564 \text {. } \\
\end{array}$ & ER/1516 & Francés & \\
\hline $\begin{array}{l}\text { Alciati, Andrea, And. Alciati Emblemata: } \\
\text { denuo ab ipso autore recognita, ac quae } \\
\text { desiderabantur, imaginibus locupletata... } \\
\text { Lugduni: apud Guilielmum Rouill., } 1566 .\end{array}$ & $\mathrm{R} / 23630$ & Francés & \\
\hline
\end{tabular}




\begin{tabular}{|c|c|c|c|}
\hline Edición & $\begin{array}{c}\text { Signaturas de } \\
\text { ejemplares }\end{array}$ & Idioma & Comentarios \\
\hline $\begin{array}{l}\text { Sánchez de las Brozas, Francisco, Francis- } \\
\text { ci Sanctii Brocensis... Comment. in And. } \\
\text { Alciati Emblemata: nunc denuò multis in } \\
\text { locis accurate recognita et quamplurimis } \\
\text { figuris illustrata. Lugduni: apud Guliel. } \\
\text { Rouillium, 1573. Ocho ejemplares. Dispo- } \\
\text { nible digitalización en Biblioteca Digital } \\
\text { Hispánica. }\end{array}$ & $\begin{array}{l}\mathrm{ER} / 1498 \\
\mathrm{ER} / 1507 \\
\mathrm{R} / 18845 \\
\mathrm{R} / 20284 \\
\mathrm{R} / 29727 \\
\mathrm{R} / 37980 \\
\mathrm{R} / 38117 \\
8 / 3305\end{array}$ & Latín & Francisco Sánchez \\
\hline $\begin{array}{l}\text { Alciati, Andrea, Omnia Andreae Alciati } \\
\text { V.C. Emblemata: cum commentariis, quibus } \\
\text { emblematum omnium aperta origine, mens } \\
\text { auctoris explicatur, \& obscura omnia du- } \\
\text { biaque illustrantur, per Claudium Minoem } \\
\text { Diuisionensem. Antuerpiae: ex officina } \\
\text { Christophori Plantini, architypographi re- } \\
\text { gij, } 1577 \text {. }\end{array}$ & $\mathrm{R} / 18594$ & Latín & Mignault \\
\hline $\begin{array}{l}\text { Alciati, Andrea, Omnia Andreae Alciati } \\
\text { V.C. Emblemata: cum commentariis... } \\
\text { per Claudium Minoem Dinionensem, } \\
\text { Editio tertia aliis multo locupletior. An- } \\
\text { tuerpiae: ex officina Christophori Plan- } \\
\text { tini..., } 1581 \text {. }\end{array}$ & $\mathrm{R} / 18849$ & Latín & Mignault \\
\hline $\begin{array}{l}\text { Alciati, Andrea, Omnia Andreae Alciati } \\
\text { v.c. emblemata: cum commentariis, quibus } \\
\text { emblematum aperta origine mens auctoris } \\
\text { explicatur, \& obscura omnia, dubiáque } \\
\text { illustrantur Adiectae ad calcem Notae pos- } \\
\text { teriores. Parisiis: apud Ioannem Richeriu, } \\
1589 .\end{array}$ & $2 / 48820$ & Latín & Mignault \\
\hline $\begin{array}{l}\text { Alciati, Andrea, Andreae Alciati V.C. Em- } \\
\text { blemata cum Claudij Minois ad eadem } \\
\text { commentariis \& notis posterioribus, quibus } \\
\text { emblematum omnium aperta origine, mens } \\
\text { auctoris explicatur, et osbcura omnia du- } \\
\text { biaque illustrantur. Lugduni: apud Haered. } \\
\text { Gulielmi Rouillii, } 1600 \text {. }\end{array}$ & $\begin{array}{l}2 / 3379 \\
3 / 33277 \\
3 / 55822 \\
3 / 64575 \\
3 / 71080\end{array}$ & Latín & Mignault \\
\hline $\begin{array}{l}\text { Alciati, Andrea, Omnia Andreae Alciati } V \text {. } \\
\text { C. Emblemata: cum commentariis quibus } \\
\text { emblematum detecta origine, dubin ommi- } \\
\text { nia, et Obswiz illustrantur: adiectae nonae } \\
\text { appendicis... per Claud Minoem. Parisis: } \\
\text { sumptibus Francisci Gueffier..., } 1602 \text { (in } \\
\text { officina Ioan Richerii). }\end{array}$ & $\begin{array}{l}2 / 2961 \\
E R / 1784\end{array}$ & Latín & Mignault \\
\hline $\begin{array}{l}\text { Andreae Alciati... Emblemata cum Claudii } \\
\text { Minois I. C. commentariis, Ad postremam } \\
\text { auctoris editionem auctis \& recognitis. } \\
\text { [Antuerpiae] ex Officina Plantiniana Ra- } \\
\text { phelengii, 1608. Digitalizado en Biblioteca } \\
\text { Digital Hispánica. }\end{array}$ & $\mathrm{R} / 20450$ & Latín & Mignault \\
\hline
\end{tabular}




\begin{tabular}{|c|c|c|c|}
\hline Edición & $\begin{array}{c}\text { Signaturas de } \\
\text { ejemplares }\end{array}$ & Idioma & Comentarios \\
\hline $\begin{array}{l}\text { Alciati, Andrea, Andreae Alciati I. V. C. } \\
\text { Emblemata elucidata... Claudij Minois } \\
\text { commentarijs quibus additae sunt eiusdem } \\
\text { auctoris notae posteriores... Lugduni: apud } \\
\text { Haeredes Gulielmi Rovillij, 1614. Digitali- } \\
\text { zado en Biblioteca Digital Hispánica. }\end{array}$ & $\begin{array}{l} \\
\\
\\
2 / 3935 \\
\mathrm{R} / 20655 \\
3 / 64573 \\
\end{array}$ & Latín & Mignault \\
\hline $\begin{array}{l}\text { López, Diego, Declaracion magistral sobre } \\
\text { las [sic] emblemas de Andres Alciato con } \\
\text { todas las historias, antiguedades, morali- } \\
\text { dad, y doctrina tocante a las buenas cos- } \\
\text { tumbres. Impresso en la ciudad de Najera: } \\
\text { por Iuan de Mongaston: a costa del autor, } \\
1615 \text {. Numerosos errores de paginación, de } \\
\text { imposición de los grabados. Varios estados. }\end{array}$ & $\begin{array}{l}4 / 53788 \\
\mathrm{R} / 2597 \\
\mathrm{R} / 14859 \\
\mathrm{R} / 23100 \\
\mathrm{R} / 23123 \\
\mathrm{R} / 23124 \\
\mathrm{R} / 26751 \\
\mathrm{R} / 31175\end{array}$ & Español & Diego López \\
\hline $\begin{array}{l}\text { Alciati, Andrea, Ommia Andreae Alciati V. } \\
\text { C. Emblemata cum commentariis quibus } \\
\text { emblematum detecta origine dubia omnia et } \\
\text { obscura illustrantur per Claud. Minoem I. } \\
\text { C. Acceserunt huic editioni Fed. Morelli... } \\
\text { corollaria et monita. Parisiis: in officina } \\
\text { Ioan Richerii: sumptibus Francisci Gueffier } \\
\text { in via D. Ioannis Lateranensis..., } 1618 .\end{array}$ & $2 / 3961$ & Español & Mignault \\
\hline $\begin{array}{l}\text { Alciati, Andrea, Andreae Alciati Emble- } \\
\text { mata cum commentariis Claudii Minois } \\
\text { I. C. Francisci Sanctii Brocensis \& notis } \\
\text { Laurentii Pignorii...; opera et vigiliis Ioan- } \\
\text { nis Thuillii... Acceserunt in sine Federici } \\
\text { Morelli... corollaria \& monita, ad eadem } \\
\text { emblemata, Novisima hac editione in con- } \\
\text { tinuam unius commentarij seriem conges- } \\
\text { tis... plusquam dimidia parte auctis. Pata- } \\
\text { vij: apud Petrum Paulum Tozzium..., } 1621 \\
\text { (ex typographia Laurentij Pasquati). }\end{array}$ & $\begin{array}{l} \\
\\
\\
2 / 5496 \\
\text { ER/1332 } \\
\end{array}$ & Latín & $\begin{array}{l}\text { Thuille, Mignault, Fran- } \\
\text { cisco Sánchez, Lorenzo } \\
\text { Pignoria }\end{array}$ \\
\hline $\begin{array}{l}\text { Alciati, Andrea, Emblemata V.C. Andreae } \\
\text { Alciati... cum facili \& compendiosa expli- } \\
\text { catione...; per Claudium Minoem... Eisus- } \\
\text { dem Alciati Vitae. Antuerpiae: ex Officina } \\
\text { Plantiniana: apud Balthasarem Moretum \& } \\
\text { viduam Joannis Moreti \& Jo. Meursium, } \\
\text { 1622. Disponible en Biblioteca Digital } \\
\text { Hispánica por digitalización de microfilm } \\
\text { 28055. Los emblemas de Alciato hasta } \\
\text { la p. 250, y en la siguiente comienzan los } \\
\text { comentarios de Mignault (Claude Minois), } \\
\text { hasta la p. 380. Sigue la vida de Alciato. }\end{array}$ & $\mathrm{R} / 20811$ & Latín & Mignault \\
\hline $\begin{array}{l}\text { López, Diego, Declaracion magistral sobre } \\
\text { las emblemas de Adres Alciato: con todas } \\
\text { las historias, antiguedades, moralidades, y } \\
\text { doctrina, tocante a las buenas constumbres. } \\
\text { Valencia: Geronimo Vilagrasa...: a costa } \\
\text { de Claudio Macé..., } 1655 \text {. Digitalizado en } \\
\text { Biblioteca Digital Hispánica el ejemplar } \\
\text { U/9525. }\end{array}$ & $\begin{array}{l} \\
\\
3 / 39318 \\
\mathrm{M} / 9525 \\
\mathrm{U} / 9525\end{array}$ & Español & Diego López \\
\hline
\end{tabular}




\begin{tabular}{|c|c|c|c|}
\hline Edición & $\begin{array}{c}\text { Signaturas de } \\
\text { ejemplares }\end{array}$ & Idioma & Comentarios \\
\hline $\begin{array}{l}\text { López, Diego, Declaracion magistral so- } \\
\text { bre los emblemas de Alciato con todas las } \\
\text { historias, antigüedades, moralidad, y doc- } \\
\text { trina, tocante a las buenas costumbres. } \\
\text { Valencia: Geronimo Vilagrasa: por costa de } \\
\text { Geronimo Sanchiz mercader de libros, a la } \\
\text { plaça de la Seo, enfrente de la puerta de los } \\
\text { Apóstoles, } 1670 \text {. Digitalizado en Biblioteca } \\
\text { Digital Hispánica el ejemplar } 3 / 33001 \text {. }\end{array}$ & $\begin{array}{r}7 \\
7 / 15150 \\
3 / 33001 \\
\end{array}$ & Español & Diego López \\
\hline $\begin{array}{l}\text { Alciati, Andrea, Emblemata... Andreae Al- } \\
\text { ciati cum facili \& compendiosa explicatio- } \\
\text { ne... Claudium Minoem... Eiusdem Alciati } \\
\text { vita. Antuerpiae: ex Officina Plantiniana: } \\
\text { sumptibus Matthaei de la Bastida..., } 1676 .\end{array}$ & $\mathrm{ER} / 4661$ & Español & Mignault \\
\hline $\begin{array}{l}\text { López, Diego, Declaracion magistral sobre } \\
\text { las [sic] emblemas de Andres Alciato con } \\
\text { todas las historias, antigüedades, morali- } \\
\text { dad, y doctrina, tocante a las buenas cos- } \\
\text { tumbres... Valencia: Francisco Mestre...: } \\
\text { a costa de Francisco Duarte, Mercader de } \\
\text { libros..., } 1684 \text {. }\end{array}$ & $\begin{array}{l} \\
2 / 26696 \\
7 / 12604 \\
\mathrm{R} / 2726 \\
\end{array}$ & Español & Diego López \\
\hline $\begin{array}{l}\text { Alciati, Andrea, V. C. Andrene Alciati... } \\
\text { Emblemata cum facili \& Compendiosa } \\
\text { explicatione, quâ obscuia illustrantur, ru- } \\
\text { bia que omnia Solvuritur per Claudium } \\
\text { Minoem; eiusdem Alciati Vita, Editio no- } \\
\text { vissima, in qua Explicationes Emblematum } \\
\text { propiis locis additae. Antuerpiae: apud } \\
\text { Henricum \& Cornelium Verdussen, } 1692 . \\
\end{array}$ & $3 / 79099$ & Latín & Mignault \\
\hline $\begin{array}{l}\text { Alciati, Andrea, V. C. Andreae Alciati... } \\
\text { Emblemata cum facili, \& compendiosa ex- } \\
\text { plicatione... per Claudium Minoem Divio- } \\
\text { nensem Eiusdem Alciati Vita, Editio novis- } \\
\text { sima... Antuerpiae: Henricus, \& Cornelius } \\
\text { Verdossen, } 1715 .\end{array}$ & $\begin{array}{l}3 / 71471 \\
\mathrm{R} / 25485\end{array}$ & Latín & Mignault \\
\hline Emblemata, [s.l.: s.e., s.a.], [1724]. & $2 / 26194$ & Latín & Mignault \\
\hline $\begin{array}{l}\text { Alciati, Andrea, V.C. Andreae Alciati... em- } \\
\text { blemata cum ... explicatione, qua obscura } \\
\text { illustrantur, dubiaque omnia solvuntur, } \\
\text { per Claudium Minoem [seud.] divisionem. } \\
\text { Eiusdem Alciati vita, Editio novissima... } \\
\text { Matriti: [Joseph de Horta], } 1733 . \\
\end{array}$ & $7 / 16021$ & Latín & Mignault \\
\hline $\begin{array}{l}\text { Emblemata cum explicatione, quâ obscura } \\
\text { illustrantur, dubiaque omnia solventur, per } \\
\text { Claudium Minoem, Ed. noviss. á mendis ex- } \\
\text { purgata. Matriti: Ex Typ. Ord. de Mercide, } \\
1749 .\end{array}$ & $2 / 4059$ & Latín & Mignault \\
\hline $\begin{array}{l}\text { Alciati, Andrea, Emblemata cum facili et } \\
\text { compendiosa explicatione... per Claudium } \\
\text { Veinoen Divisionensem. Episdem Alciati } \\
\text { vitae, Editio novissimo... Matriti: Ex Typo- } \\
\text { graphia Pantaleonis Aznar, } 1781 .\end{array}$ & $3 / 20072$ & Latín & Mignault \\
\hline
\end{tabular}


BiBLIOGRAFÍA

Adams, Alison, Stephen Rawles y Alison Saunders (1999). A Bibliography of French Emblem Books of the Sixteenth and Seventeenth Centuries, t. 1, A-K. Geneva: Droz.

Alciato at Glasgow <https://www.emblems.arts.gla.ac.uk/alciato/bib-desc.php?id=A31a> [Consulta: 12/12/2019].

CAmpa, Pedro F. (1989). «Diego Lopez’s Declaración magistral de las emblemas de Alciato: A Seventeenth-Century Spanish Humanist's View». En Peter M. Daly (ed.), Andrea Alciati and the Emblem: Essays in honor of Virginia Woods Callahan. New York: AMS Press, pp. 223-248.

CAmpa, Pedro F. (1990). Emblemata Hispanica. An Annotated Bibliography of Spanish Emblem Literature to the Year 1700. Durham / London: Duke University Press.

CAmpa, Pedro F. (2001). «Emblemata Hispanica: Addenda et Corrigenda». Emblematica. An Interdisciplinary Journal for Emblem Studies, 11, pp. 327-376.

Castellano López, Abigail (2018). Aulo Persio Flaco, traducido en lengua castellana por Diego López. Con declaración magistral en que se declaran todas las historias, fábulas, versos dificultosos y moralidad que tiene el poeta: edición crítica y estudio. Luis María Gómez Canseco y Fernando Navarro Antolín (dirs.) [tesis doctoral]. Huelva: Universidad de Huelva <http://rabida.uhu.es/dspace/handle/10272/15621> [Consulta: 18/10/2019].

DrYSDALL, Denis L. (2001). «The Emblems in two unnoticed items of Alciato's correspondence». Emblematica, 11, pp. 379-391.

Enenkel, Karl A. E. (2018). The invention of the Emblem Book and the transmission of Knowledge, ca. 1510-1610. Leiden: Brill.

Exemplario contra los engaños y peligros del mundo [Calila y Dimna español], [Zaragoza]: Pablo Hurus, 1493 <http://bdh.bne.es/bnesearch/detalle/bdh0000174126> [Consulta: 18/10/2019].

García Arranz, José Julio (en prensa). «Notas en torno a las picturae de la primera edición de la Declaración magistral sobre las emblemas de Andrés Alciato de Diego López (Nájera, 1615)». Se espera su publicación en las actas del XII Congreso Internacional de la Sociedad Española de Emblemática.

GreEn, Henry (1872). Andrea Alciati and his books of emblems: a biographical and bibliographical study. London: Trübner \& Co.

Heckscher, William S. (1981). «Pearls from a Dung-Heap: Andrea Alciati's 'Offensive' Emblem: "Adversus Naturam Peccantes"». En Moshe Barasch and Lucy Freeman Sandler (eds.), Art the Ape of Nature: Studies in Honor of H. W. Janson. New York: Abrams, pp. 291-311.

HeCKscher, William S. (1989). The Princeton Alciati companion: a glossary of neo-Latin words and phrases used by Andrea Alciati and the emblem book writers of his time, including a bibliography of secondary sources relevant to the study of Alciati's emblems. New York: Garland.

Index Emblematicus (1985). Andreas Alciatus, 1. The Latin Emblems, Indexes and Lists. Peter M. Daly, Virginia W. Callahan and Simon Cuttler (eds.). Toronto: University of Toronto Press. 
Izquierdo IzQuierdo, José Antonio (1989). Diego López o el virgilianismo español en la escuela del Brocense. Cáceres: Institución Cultural «El Brocense» / Diputación Provincial de Cáceres.

Landwehr, John (1972). German Emblem Books 1531-1888. A Bibliography. Utrecht: Haentjens Dekker and Gumbert.

LóPEz PozA, Sagrario (2016). «Los libros de emblemas: género editorial, género literario y fuente de erudición». Ínsula, 833, pp. 8-10<http://hdl.handle.net/2183/17558> [Consulta: 26/01/2021].

Manning, John (1997). «The Dungheap Revisited: A Reconsideration of Alciato's Obscene Emblem». En Peter M. Daly and Daniel S. Russell (eds.), Emblematic Perceptions: Essays in Honor of William S. Heckscher on the Occasion of His Ninetieth Birthday. Baden: Valentin Koerner, pp. 123-134.

Medeiros AraúJo, Filipa (2020). «Sebastian Stockhamer e o desafio de comentar Alciato "com o peso do Etna sobre os ombros"». Imago. Revista de Emblemática y Cultura Visual, 20, pp. 83-104. DOI: https://doi.org/10.7203/imago.20.17744.

Merino Jerez, Luis (1989). «Diego López o la presencia de la Minerva en el Arte Reformado de Nebrija». En Actas del Symposio Internacional IV Centenario de la publicación de la Minerva (1587-1987). Cáceres: Institución Cultural «El Brocense», pp. 189-201.

Merino Jerez, Luis y Jesús Ureña (2003). «On the Date of Composition of El Brocense's Commentaria in Alciati Emblemata». Emblematica. An Interdisciplinary Journal for Emblem Studies, 13, pp. 73-96.

Morcillo Expósito, Guadalupe (ed.) (2002). La gramática de Diego López. Cáceres: Universidad de Extremadura.

Ratio Studiorum (1599). The Jesuit Ratio Studiorum of 1599. Translated into English, with an Introduction and Explanatory Notes by Allan P. Farrell, S. J. (1970). Washington: Conference of Major Superiors of Jesuits.

Russell, Daniel (1985). The Emblem and Device in France. Lexington, K.Y: French Forum.

SaAvedra Fajardo, Diego (1999). Empresas políticas. Sagrario López Poza (ed.). Madrid: Cátedra.

ScHolz, Bernhard (1990). «The Augsburg Edition of Alciato's Emblemata: A Survey of Research». Emblematica, 5, pp. 213-254.

Tung, Mason (1989). «Towards a new Census of Alciati's Editions». Emblematica, 4, pp. $135-176$.

Vedova, Giuseppe (1836). Biografia degli scrittori padovani. Padova: Coi Tipi della Minerva, t. 2.

Recibido: $25 / 02 / 2021$

Aceptado: 12/04/2021 


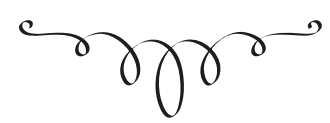

El libro de emblemas de Andrea Alciato en la Biblioteca Nacional de España

RESUMEN: Al final del siglo XV y comienzos del XVI los impresores exploraban fórmulas para publicar un género de moda, el de los proverbios ilustrados, que eran demandados por su interés didáctico-moralizante. Ensayan procedimientos que se concretan en los libros de emblemas, cuyo éxito inmediato (por reunir imagen y palabra) los convierte en un género a la vez literario y editorial. Este artículo presenta una introducción a las modalidades emblemáticas para centrarse luego en el Emblematum liber de Andrea Alciato, considerado como primer libro de emblemas (1531), y se atiende a su éxito editorial, la producción de comentarios eruditos sobre él y su difusión impresa, así como la traducción de la obra al español. Finalmente, se indican las ediciones (y ejemplares) de la obra de Alciato, hasta el siglo XVIII (así como algunos manuscritos) con que cuenta la Biblioteca Nacional de España.

Palabras clave: Andrea Alciato, Emblemática, libros de emblemas, Biblioteca Nacional de España, imprenta siglos XVI a XVIII, comentarios eruditos humanísticos.

Andrea Alciato's book of emblems in the National Library of Spain

ABSTRACT: In the late 15th and early 16th centuries, printers were exploring formulas to publish a fashionable genre, that of illustrated proverbs, which were in demand for their didactic-moralizing interest. They rehearse procedures that are specified in the emblem books, whose immediate success (by bringing image and word together) makes them a genre that is both literary and editorial. This article presents an introduction to the emblematic modalities to focus later on the Emblematum liber by Andrea Alciato, considered as the first book of emblems (1531), and focuses on its publishing success, the production of scholarly commentaries on it and its printed diffusion, as well as the translation of the work into Spanish. Finally, the editions (and copies) of Alciato's work (until the 18th century) are reported, as well as some manuscripts, preserved in the National Library of Spain.

Keywords: Andrea Alciato, Emblem Studies, Emblem books, National Library of Spain, Printing press 16th to 18th centuries, Humanistic scholarly commentaries. 